\title{
Tectônica transcorrente Mesozoica-Cenozoica no Domo de Lages - Santa Catarina
}

\author{
Rômulo Machado ${ }^{1 *}$, Luis Fernando Roldan², Patrícia Duringer Jacques ${ }^{3}$, \\ Elvo Fassbinder ${ }^{4}$, Alexis Rosa Nummer ${ }^{5}$
}

\begin{abstract}
RESUMO Este trabalho apresenta o estudo multiescala dos lineamentos estruturais que afetam as rochas alcalinas associadas ao Domo de Lages, situado na borda Leste da Bacia do Paraná, em Santa Catarina. Foram analisadas imagens de satélite (Landsat-TM) e do projeto Shuttle Radar Topography Mission (SRTM) e realizados estudos estruturais em pedreiras de rochas alcalinas do domo. Os resultados obtidos mostram correlação entre os fotolineamentos extraídos das imagens e as falhas analisadas nas pedreiras, com destaque para as direções N-S (NNE a NNW) e E-W (ENE a ESE) e, secundariamente, NE e NW. Estas estruturas são relacionadas, em grande parte, com a reativação de descontinuidades do embasamento. As duas primeiras direções correspondem a falhas transcorrentes destral e sinistral, respectivamente. A formação destas estruturas é compatível com um campo de tensão $\sigma_{1}$ orientado NE-SW, cuja idade situa-se entre Eocretáceo e o Terciário.
\end{abstract}

Palavras-chave: Domo de Lages; estudo multiescala; falhas transcorrentes; geoprocessamento.

\begin{abstract}
Mesozoic-Cenozoic transcurrent tectonics in the Lages Dome, Santa Catarina. This work presents the multiscale study of structural lineaments that affect alkaline rocks associated to the Lages Dome, situated in the Eastern edge of the Paraná Basin, Santa Catarina state, Brazil. We analyzed satellite images (Landsat-TM) and Shuttle Radar Topography Mission (SRTM) project and carried out structural studies of alkaline rocks in quarries of the dome. The results show correlation between the lineaments extracted from the images and faults analyzed in quarries, especially around the NS directions (NNE to NNW) and EW (ENE to ESE) and, secondarily, NE and NW. These structures are largely related to reactivation of basement discontinuities. The first two directions correspond to dextral and sinistral transcurrent faults, respectively. Formation of these structures is compatible with a field of tension with axis oriented NESW, whose age ranges from the Late Cretaceous and Tertiary.
\end{abstract}

Keywords: Lages Dome; multiescale study; transcurrent faults; geoprocessing.

INTRODUÇÃO O arcabouço estrutural da Bacia do Paraná é significativamente controlado pela reativação de estruturas presentes no seu embasamento (Northfleet et al. 1969), em particular aquelas geradas durante o ciclo Brasiliano, com a sua configuração sendo influenciada diretamente pelos arqueamentos e flexuras desse embasamento (Almeida 1986, 2000, Zalán et al. 1987,1990).

Os arqueamentos e flexuras influenciaram a evolução tectono-sedimentar da Bacia do Paraná provavelmente ao longo de toda a sua história (Almeida 2000). Tais estruturas, no entanto, se manifestaram de forma mais vigorosa a partir do Mesozoico, particularmente junto à borda Leste da bacia, quando houve a ruptura do continente Gondwana e a formação do Atlântico Sul, culminando, no Cretáceo Inferior, com a geração do magmatismo básico, ligado à Formação Serra Geral.
Este magmatismo afetou toda a bacia, com espessura superior a 1,5 mil $\mathrm{m}$, atingida em um poço perfurado na região de Porto Epitácio (SP).

Alguns arcos parecem ser feições estruturais bastante novas na história da bacia, com atividade já evidenciada a partir do final do Paleozoico e início do Mesozoico, a exemplo dos arcos de Ponta Grossa e Alto Parnaíba e do Sinclinal de Torres, enquanto outros, como os do Rio Grande e de Campo Grande, parecem ser mais antigos, com atuação já manifesta a partir do Devoniano Médio e início do Carbonífero Superior (Almeida 2000). O Arco de Ponta Grossa assumiu a configuração que hoje se apresenta somente no Triássico-Jurássico, separando as bacias Piramboia e Rosário do Sul (Almeida 1983, Zalán et al. 1990). Durante a Reativação Wealdeniana (Almeida 1967),

${ }^{1}$ Universidade de São Paulo - USP, São Paulo (SP), Brasil. E-mail: rmachado@usp.br

${ }^{2}$ Tratch-Mundi Gerenciamento Ambiental Ltda, São Paulo (SP), Brasil. E-mail: 1froldan@gmail.com

${ }^{3}$ Companhia de Pesquisa de Recursos Minerais - CPRM, Rio de Janeiro (RJ), Brasil. E-mail: patricia.jacques@cprm.gov.br

${ }^{4}$ Universidade Federal do Paraná - UFPR, Curitiba (PR), Brasil. E-mail: elvo@ufpr.br

${ }^{5}$ Universidade Federal Rural do Rio de Janeiro - UFRJ, Itaguaí (RJ), Brasil. E-mail: nummer@ufrrj.br

*Autor correspondente 
entre o Jurássico Superior e o Cretáceo Inferior pré-Aptiano, houve o soerguimento desta estrutura (mínimo de 7,5 km: IPT 1980), acompanhado de expressiva intrusão de enxames de diques básicos da Formação Serra Geral, paralelos ao eixo do arco.

O Sinclinal de Torres, com direção subparalela ao Arco de Ponta Grossa, é considerado uma estrutura nova na história da bacia. $\mathrm{O}$ mapa de isópacas da Formação Rio do Rasto sugere atividade no fim do Permiano Superior, que se intensificou durante o Mesozoico (Northfleet et al. 1969, Almeida 2000). No Triássico, a subsidência foi pouco importante, pois a Formação Botucatu apresenta-se na região com espessura inferior a $100 \mathrm{~m}$ (Northfleet et al. 1969), porém no Jurássico Superior ele experimentou uma subsidência notável (Cordani \& Vandoros 1967).

O Arco de Assunção, situado na divisa do Brasil com o Paraguai, divide as bacias do Paraná e do ChacoParaguai e é considerado uma estrutura desta época ou mais antiga, do Eodevoniano (Zalán et al. 1990), com sua atividade sendo refletida no caráter arenoso da Formação Ponta Grossa (Almeida 2000). Trata-se de uma feição positiva originada pela sobrecarga litosférica imposta ao continente pelo cinturão andino (Milani 2004).

Almeida (1983), ao discutir as relações tectônicas das rochas alcalinas mesozoicas na porção meridional da Plataforma Sul-Americana, considera a possibilidade da intrusão de Lages estar associada à reativação tectônica de falhas tardibrasilianas situadas na parte Sul de Santa Catarina, bem como ressalta o fato do Domo de Lages estar localizado na região de inflexão entre duas grandes estruturas tectônicas, o Arco de Ponta Grossa e o Sinclinal de Torres (Fig. 1). Vários trabalhos têm ressaltado a importância da reativação de falhas transcorrentes já existentes no embasamento da Bacia do Paraná e sua influência na formação de altos estruturais nas unidades fanerozoicas (Soares et al. 1982, 1996, Zalán et al. 1987, 1990, Almeida 1983, 2000, Riccomini 1995a, Rostirolla et al. 2000, dentre outros).

O magmatismo básico da Formação Serra Geral, por exemplo, se desenvolveu preferencialmente em áreas de consolidação tardia do Brasiliano, assim como o fenômeno de reativação tectono-magmática e evolução tectono-sedimentar mesozoica, incluindo também o magmatismo alcalino, que não deixam dúvidas quanto à sua correlação com os processos que levaram à ruptura do Gondwana e abertura do Atlântico Sul (Almeida 1983, 2000; Zalán et al. 1987, 1990).
O flanco Leste da Bacia do Paraná corresponde à região crustal que foi profundamente afetada pelo rifteamento do At lântico Sul e abertura do oceano (Zalán et al. 1987, Milani \& Thomaz Filho 2000). O levantamento e erosão ocorridos desde o início do Cretáceo foram responsáveis pela remoção de importantes quantidades de sedimentos paleozoicos da região. Foi nesse ambiente tectônico que se processou o extenso vulcanismo basáltico toleítico e ácido associado, bem como a colocação de enxames de diques básicos e a primeira fase do magmatismo alcalino disposto às bordas da referida bacia (Almeida 1983).

O Domo de Lages, região do presente estudo, trata-se de uma estrutura alongada na direção NO ( $\sim 35 \mathrm{~km}$ x 25/30 km), que se insere no contexto das feições estruturais mais novas da borda da Bacia do Paraná no Leste do Planalto Catarinense, cuja estruturação associa-se à intrusão de rochas alcalinas com idade ao redor de $75 \mathrm{Ma}$ (Scheibe 1986, Scheibe et al. 1985, Machado \& Teixeira 2008).

Este trabalho apresenta o estudo geométrico e cinemático de falhas que afetam rochas alcalinas associadas ao Domo de Lages, bem como avalia o quadro de tensões vigentes e as possíveis idades de geração dessas estruturas. Apresenta também os padrões de fotolineamentos obtidos a partir da análise de imagens de satélite (Landsat e SRTM) e os compara com as direções das estruturas analisadas em campo.

\section{CONTEXTO TECTÔNICO REGIONAL}

Bacia do Paraná A evolução tectônica da Bacia do Paraná teve uma estreita relação com o desenvolvimento dos cinturões móveis paleozoicos na porção Sulocidental do Gondwana, onde os ciclos orogênicos exerceram influência decisiva na criação de espaço para a acomodação das pilhas sedimentares e história deformacional da bacia (Ramos et al. 1986, Milani 1997, Milani \& Ramos 1998, Milani \& Thomaz Filho 2000).

O eixo principal de deposição da Bacia do Paraná esteve orientado próximo da direção N-S, com ligeira mudança para NO durante o Devoniano. Daí em diante apresentando tendência para N-NE, direções estas que são claramente evidenciadas nos mapas de isópacas disponíveis sobre as diferentes unidades estratigráficas que compõem a bacia (Northfleet et al. 1969). Nota-se, já a partir da deposição da Formação Ponta Grossa, a divisão da bacia em duas sub-bacias, uma a Norte, com depocentro na altura de Alto Garças (MT), e outro a Sul, com depocentro entre Londrina e Ponta 
Grossa (PR), separados por um alto do embasamento situado na região de Três Lagoas, divisa de Mato Grosso do Sul com São Paulo (Fig. 7 em Northfleet et al. 1969, Fig. 9 em Zalán et al. 1990).

Segundo Loczy (1968), a estrutura tectônica da Bacia do Paraná é o resultado direto de movimentos verticais vinculados a falhas normais, não havendo relação com compressões tangenciais. Ele chama a atenção para as falhas principais com direção NNE, no Sul do Paraná e em Santa Catarina, e salienta sua coincidência com as direções do embasamento. Ainda menciona falhas NW e WNW geralmente preenchidas por diques de diabásio.

Estudos geofísicos (aeromagnéticos) realizados na bacia mostram a existência de alinhamentos estruturais NW-SE (Guapiara, São Jerônimo-Curiúva, Rio Alonso e Rio Piquiri), associados ao Arco de Ponta Grossa, que se estendem até a altura da calha do Rio Paraná, com extensão superior a 600 km (Ferreira 1982).

Zalán et al. $(1987,1990)$ destacam, no arcabouço estrutural da Bacia do Paraná, três orientações principais: NW-SE, NE-SW e E-W. As duas primeiras são as mais importantes e representam zonas de fraqueza antigas que foram recorrentemente ativas durante a evolução da bacia. Estruturas em flor, dobras e falhas inversas escalonadas, ou extensas falhas normais, estão associadas a esses lineamentos. As falhas NW foram fortemente reativadas durante a quebra do Gondwana no Juro-Cretáceo, enquanto as NE permaneceram inativas durante esse evento. As falhas NE têm sido amplamente reconhecidas no embasamento da bacia e encontram-se relacionadas a movimentações transcorrentes tardibrasilianas. Ao contrário das anteriores, estas não se acham preenchidas pelos diques básicos do Eocretáceo. Os lineamentos E-W são detectados em mapas aeromagnéticos e em imagens Landsat e foram ativos provavelmente a partir do Triássico.

Freitas et al. 2002, ao estudarem os lineamentos estruturais em escala 1:250.000 na região Oeste de Santa Catarina, com uso de imagens Landsat e mosaicos de radar do Projeto RADAMBRASIL, destacam as direções N30-50E e N40-60W e, secundariamente, N-S e E-W. Descrevem ainda falhas verticais N70E com cerca de $135 \mathrm{~km}$ de extensão, e possíveis falhas N-S, sugeridas pela presença de fontes de poços hipotermais ao longo do Rio das Antas.
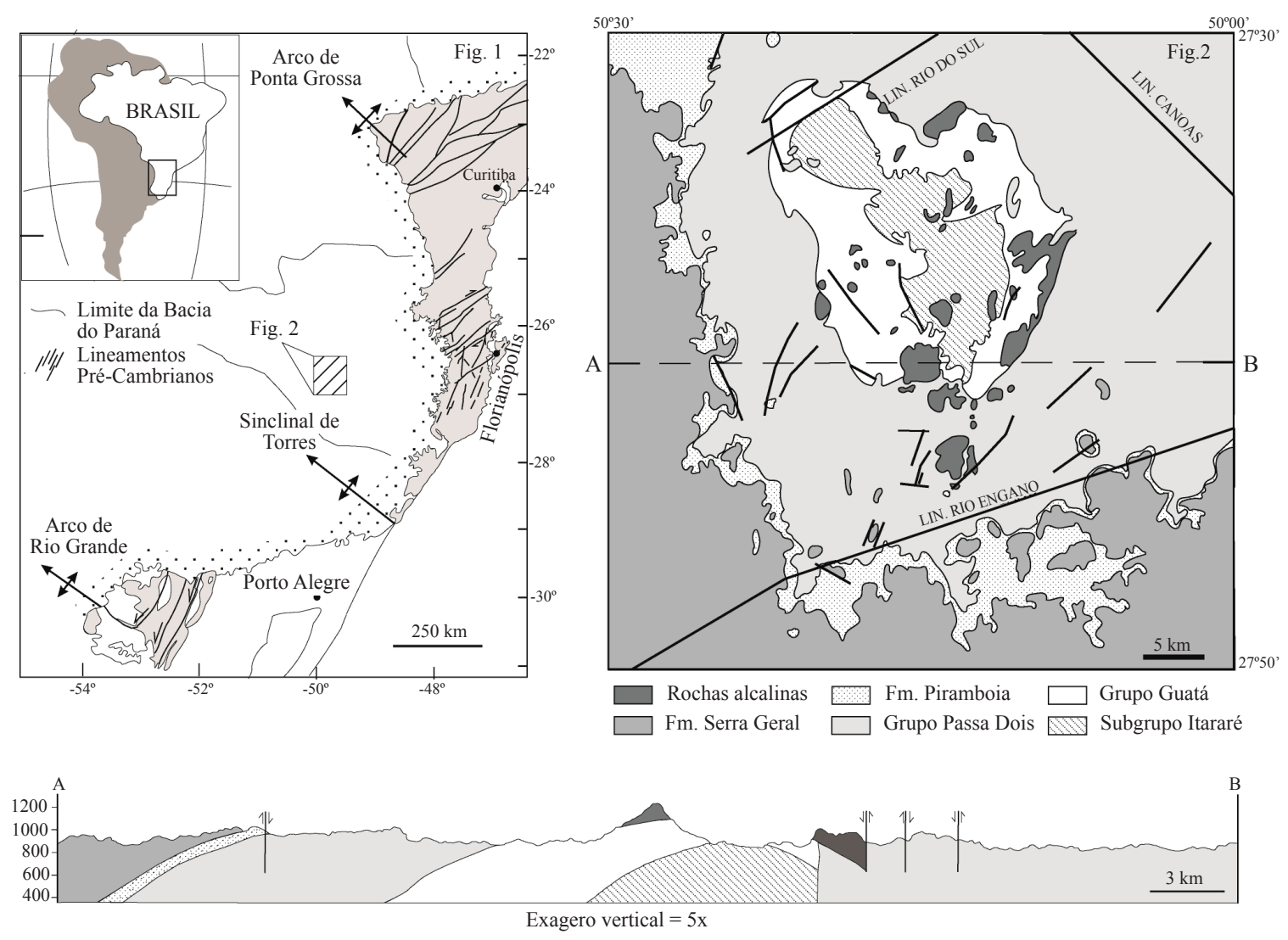

Figura 1 - Contexto geológico regional da área estudada com indicação das principais feições estruturais da borda Leste da Bacia do Paraná no Sul do Brasil e dos escudos Catarinense, Paranaense e Sul-Rio-Grandense (modificado de Schobbenhaus Filho et al. 1984, Bitencourt 1996, Almeida 2005).

Figura 2 - Mapa geológico da região do Domo de Lages, SC (simplificado de Roldan 2007, Roldan et al. 2010). 
Estudos de lineamentos estruturais no Domo de Lages, incluindo análise integrada de diferentes produtos digitais (imagens de satélite, mapas diversos, de rugosidade, declividade, morfométrico, modelo digital de terreno, etc.), destacam cinco direções principais: WNW N-S, NNE, ENE e NW (Roldan 2007, Roldan et al. 2010). As três primeiras apresentam maiores frequências acumuladas, e as três últimas, maiores comprimentos acumulados. Os lineamentos mais extensos são ENE (4 a 40 km) e, secundariamente, N-NE e NW. Ocorrem falhas transcorrentes destrais N-S, NNE e NE, e sinistrais WNW e E-W, ambas afetando as rochas alcalinas associadas ao domo (Roldan 2007).

Jacques et al. 2010 estudam os lineamentos estruturais na borda Leste da bacia em Santa Catarina e no seu embasamento com o uso de produtos digitais (imagens Landsat e do projeto Shuttle Radar Topography Mission - SRTM, escalas 1:100.000 e 1:500.000) e definem as direções N-S e NNE-SSW (embasamento), NW-SE e N-S (Sequência Gondwânica) e NE-SW e NW-SE (Formação Serra Geral).

Escudo Catarinense e Sul-Rio-Grandense $\mathrm{O}$ arcabouço estrutural do Escudo Catarinense evidencia dois padrões principais: um N55E (porção central e setentrional do escudo) e outro ao redor de N20E (porção meridional). O primeiro é bem evidente no domínio do Grupo Brusque, com os granitos das suítes São Valsungana, São João Batista e Nova Trento, com idades entre 650 e $580 \mathrm{Ma}$ (Bitencourt \& Nardi 2000, Bitencourt et al. 2008, Basei et al. 2000). Este domínio acha-se limitado a NW pela Zona de Cisalhamento Itajaí-Perimbó e a sudeste pela Zona de Cisalhamento Major Gercino, ambas do Neoproterozoico e com cinemática destral (Passarelli 1996, Bitencourt et al. 2008). Este mesmo padrão estrutural é encontrado no pré-cambriano paranaense, com realce para as orientações N30-40E e N60E (Schobbenhaus Filho et al. 1984).

O segundo padrão evidencia-se no domínio do Batólito Florianópolis (ou Pelotas) e do Complexo Metamórfico Camboriú de idades, respectivamente, neoproterozoica e paleoproterozoica (Basei et al. 2000, Bitencourt et al. 2008).

Lineamentos estruturais N10E e N60E, evidenciados em imagens de satélite Landsat e em campo no distrito fluorítico do Sudeste de Santa Catarina, foram reativados durante o Mesozoico como falhas transcorrentes, destrais e sinistrais, com a mineralização de fluorita sendo encontrada em falhas N30-40E (Ferreira \& Almeida 1989).
Almeida (2005) caracteriza na Bacia do Camaquã quatro grupos de falhas com idades e campos de esforços distintos: três deles transcorrentes (ENE, ESE, NNE e NNW), dois mais antigos (Neoproterozoico/Cambriano e Cambriano) e um mais novo (Triássico), e um grupo de falhas normais (ESE), de idade pós-triássica. As falhas transcorrentes triássicas são de cinemática não definida; têm direção ESE e relacionam-se a um evento compressivo NE. As falhas normais pós-triássicas apresentam aproximadamente a mesma direção das anteriores, sendo ligadas a um campo de esforço distensivo próximo de N-NE, possivelmente relacionado ao evento Eocretáceo da Formação Serra Geral e ao soerguimento do Alto Estrutural de Rio Grande.

A análise comparativa de lineamentos de áreas do embasamento e da bacia, realizada a partir de sensores remotos e geofísicos (mapas magnetométricos e gravimétricos), na porção Norte de Santa Catarina e Sul do Paraná, confirma as estruturas regionais delineadas anteriormente e realça os lineamentos NE (N60-70E e N30-40E), NW, NNW e E-W, sendo este último de continuidade regional, porém restrito a "corredores" (Freitas 2005, Freitas \& Rostirolla 2005).

Estruturas transcorrentes na bacia Os estudos estruturais e geofísicos realizados no Paraná (Quatiguá, Prudentópolis e Jaguariaíva), incluindo a divisa com Santa Catarina, evidenciam falhas transcorrentes no $\mathrm{NE}$, sinistral e destral, e falhas distensionais no NW, estas exibindo cinemática sinistral (Rostirolla et al. 2000, Machado \& Rostirolla 2005, Freitas 2005, Freitas \& Rostirolla 2005). As primeiras são consideradas mais antigas (Permo-Triássico) e as duas últimas, mais novas (Mesozoico), tendo sido reativadas, ou neoformadas, no Eocretáceo, condicionando o magmatismo básico da Formação Serra Geral (Rostirolla et al. 2000, Machado \& Rostirolla 2005, Mezzomo \& Rostirolla 2005). As transcorrências sinistrais E-W da região de Jaguariaíva são, provavelmente, posteriores às estruturas descritas acima (Machado \& Rostirolla 2005).

A tectônica transcorrente (destral, ENE e WSW; e sinistral, NNW e NW), caracterizada no Alto Estrutural de Pitanga - borda NE da Bacia do Paraná em São Paulo - é comparável ao que foi descrito para a estrutura de Quatiguá no Paraná (Soares 1976, Soares et al. 1996, Riccomini 1995a, Rostirolla et al. 2000, Souza 1997, 2002).

Estudos integrados (estruturais, sensores remotos, aerogeofísicos - gravimétricos e magnetométicos) realizados na divisa do Paraná com Santa Catarina evidenciaram cinco direções principais de estruturas regionais: 
N60-70E, N30-40E, NNE, NNW e NW (Freitas 2005). Foram definidos dois eventos deformacionais: um mais antigo $\left(\sigma_{1}-\mathrm{I}\right)$, com tensão máxima principal $\left(\sigma_{1}\right)$ orientada N-NW-S-SE; e outro mais novo $\left(\sigma_{1}-\right.$ II $)$, com tensão máxima principal $(\sigma 1)$ orientada ENE-WSW. Estas direções $\left(\sigma_{1}-\mathrm{I}\right.$ e $\left.\sigma_{1}-\mathrm{II}\right)$ são semelhantes às fases deformacionais $\mathrm{D}_{1}$ e $\mathrm{D}_{2}$, com idades, respectivamente, do Eocretáceo e do Eocretáceo ao Terciário, definidas no Arco de Ponta Grossa (Strugale 2002, Strugale et al. 2007). O primeiro evento foi em regime extensional e o segundo, transtensional. $\mathrm{O}$ evento $\mathrm{D}_{1}$, com rotação horária $\left(20 \mathrm{a} 30^{\circ}\right)$ do $\left(\sigma_{1}\right)$ entre NNW a N-S, controlou a intrusão do enxame de diques NW-SE do arco, soergueu blocos na sua parte central e gerou falhas tipo tesoura na mesma direção dos diques. Já o evento $D_{2}$, com $\left(\sigma_{1}\right)$ próximo de $E-W$, promoveu a reativação das paredes dos diques e gerou bandas de deformação em arenitos.

DOMO DE LAGES O Domo de Lages, localizado a cerca de $120 \mathrm{~km}$ da borda Leste da Bacia do Paraná em Santa Catarina, situa-se entre duas importantes feições tectônicas da bacia: o Arco de Ponta Grossa, a Norte, e o Sinclinal de Torres, a Sul (Fig. 1). O primeiro, com direção NW, já manifestava tendência ao soerguimento desde o Paleozoico, com possíveis reflexos na Formação Furnas (Northfleet et al. 1969, Fúlfaro 1971), configurando-se claramente como uma área positiva no Permiano Médio/Permiano Superior, quando separou as sub-bacias de São Paulo e de Santa Catarina (Almeida 1983, 2000).

O Domo de Lages, localizado imediatamente a Norte da cidade homônima, corresponde a uma das estruturas tectônicas mais espetaculares da borda Leste da Bacia do Paraná em Santa Catarina, diferenciando-se das demais estruturas dômicas da bacia pela sua associação com rochas alcalinas. Estas rochas ocorrem principalmente na forma de soleiras e apresentam maior incidência nas partes Sul e Sudeste da estrutura. Na sua parte Central são expostas as unidades mais antigas da bacia (Subgrupo Itararé), e em direção à periferia, as unidades sucessivamente mais novas (grupos Guatá e Passa Dois, e Formações Piramboia e Serra Geral) (Fig. 2).

Os grupos acima são de idade permocarbonífera e, juntamente com a Formação Piramboia do Eotriássico, fazem parte da Supersequência Gondwana I de Milani (1997) e Milani et al. (2007). Já a Formação Serra Geral integra a Supersequência Gondwana II destes mesmos autores, com idade entre 137 a $127 \mathrm{Ma}$ (Milani et al. 2007).
Trabalhos anteriores As primeiras pesquisas geológicas realizadas na região de Lages remontam à década de 1930 e foram voltadas à pesquisa de petróleo. Nesta ocasião já se identificou a estrutura de um grande domo, o Domo de Núcleo Vulcânico (Paiva 1933), com um núcleo de rochas intrusivas alcalinas (Morro do Tributo) circundado por rochas sedimentares mais antigas (folhelho Irati). Verificou-se que, a partir do Morro do Tributo, as camadas possuíam mergulhos de 10 a $15^{\circ}$ e direções variáveis (Paiva 1933). Três sondagens realizadas na região com profundidades de $290 \mathrm{~m}$ (3 km a NE de Lages), $130 \mathrm{~m}$ (35 km a Oeste de Lages) e $500 \mathrm{~m}$ (Correia Pinto), respectivamente, evidenciaram a presença de soleiras de fonólito, relacionadas a um stock central (Tributo, Seringa, Cêrro Alto) alimentador (Paiva 1933).

Barbosa (1933) fez a primeira descrição pormenorizada das rochas alcalinas de Lages e classificou os sienitos nefelínicos da intrusão do Morro do Tributo, descritos por Paiva (1933) como fonolitos típicos, e identificou sölvsbergito e tinguaíto em amostras de sondagem, estes últimos com textura traquítica e contendo aegerina. Descreveu ainda lamprófiro de monchiquito típico, brecha fonolítica com alteração hidrotermal e augitito de Capão Alto.

Scorza (1937), ao descrever a petrografia de amostras de rochas ígneas coletadas por Loczy na década de 1960, denominou de microfoiaito as rochas do Morro do Tributo e classificou como olivinamelilito uma rocha melanocrática com fenocristais de olivina serpentinizada e cristais de biotita de até $12 \mathrm{~mm}$. Descreveu, na ocasião, uma rocha efusiva porfirítica com fenocristais de plagioclásio (até 1,5 $\mathrm{cm}$ ), aegerina-augita, nefelina e kersurtita (kaersutita), da família dos essexitos, que classificou como dancalito.

As rochas alcalinas associadas ao domo têm despertado grande atenção de pesquisadores brasileiros e estrangeiros, havendo na literatura inúmeros trabalhos que abordam principalmente os aspectos mineralógicos, geoquímicos e petrológicos (Scheibe 1980, 1986, Furtado \& Scheibe 1989, Traversa et al. 1994 e 1996, Comin-Chiaramonti et al. 2002, Barabino et al. 2007).

Estudos específicos destas rochas conduzidos por Scheibe $(1980,1986)$ permitiram separá-las em alcalinas leucocráticas (fonólitos, analcima traquitos e nefelina sienitos) e ultrabásicas alcalinas (olivina melilitos e lamprófiros, geralmente na forma de diques), além de carbonatitos, kimberlitos e brechas de chaminé, compondo o que então foi denominado Distrito Alcalino de Lages. Os dados radiométricos 
disponíveis mostram idades entre $78 \mathrm{Ma}$ a $63 \mathrm{Ma}(\mathrm{K} / \mathrm{Ar})$, entre 76 a $73 \mathrm{Ma}(\mathrm{Ar} / \mathrm{Ar})$ e de $81 \pm 8 \mathrm{Ma}(\mathrm{Rb} / \mathrm{Sr})$ (Scheibe et al. 1985, Scheibe 1986, Machado \& Teixeira 2008).

Loczy (1966), ao realizar estudos sistemáticos na região do Domo de Lages, definiu a estrutura como um domo vulcânico, do tipo perfurante, com formato circular. Segundo o autor, as camadas dos grupos Itararé e Guatá, do Supergrupo Tubarão (concepção de Schneider et al. 1974), integrantes da Supersequência Gondwana I de Milani et al. (2007), juntamente com o Grupo Passa Dois, foram elevadas de cerca de 1,1 mil a 1,2 mil m. Considerou o magmatismo alcalino como posterior à deposição do Membro Morro Pelado (Formação Rio do Rasto) e dos arenitos. Descreveu, na parte central da estrutura, uma cobertura sedimentar intensamente fraturada, com falhas de empurrão associadas, que exibe rochas mais antigas no núcleo e mais novas na parte externa. Esta cobertura (grupos Itararé e Guatá) foi elevada como um bloco único, formando uma capa sub-horizontal (8 km x 3-4 km de largura) acima da massa de microfaiaito e dancalito (Loczy 1968).

A cartografia geológica em escala de semidetalhe desenvolvida na região mostrou que algumas dessas ocorrências de rochas alcalinas, descritas inicialmente como corpos intrusivos do tipo stocks, a exemplo do Morro do Tributo (o ponto culminante da região, com $1.220 \mathrm{~m}$ ), correspondem a corpos estratoides do tipo soleiras, intrusivos preferencialmente na parte superior da Formação Serra Alta. Estes corpos têm espessura em geral não superior a $100 \mathrm{~m}$ e possuem depósitos de bauxita associados a eles.

Estudos multiescala de fotolineamentos com base em imagens Landsat e do projeto SRTM, realizados no Domo de Lages, destacam cinco direções estruturais: WNW, N-S, NNE, ENE e NW (Roldan 2007, Roldan et al. 2010). A estruturação do domo foi relacionada a um regime de esforços compressivos NE-SW, que permaneceu ativo após a intrusão e resfriamento das alcalinas e foi ainda responsável pela geração de falhas transcorrentes destrais (NNE-SSW e NE-SW) e sinistrais (E-W), que afetam as rochas da região (Roldan 2007).

\section{MATERIAIS E MÉTODOS}

Geoprocessamento Com base em ferramentas de Sistemas de Informações Geográficas (SIG) foi implementado um banco de dados georreferenciados visando à sistematização dos dados disponíveis (mapas, fotos e imagens) e à incorporação dos dados de campo. Para essa tarefa foi utilizado o programa de computador ArcGis, versão 9.0. As imagens de satélite foram tratadas no programa ENVI, versão 4.2, e foram georreferenciadas e incorporadas ao banco de dados. Utilizou-se como base geológica o mapa geológico em escala 1:100.000 de Scheibe (1986), com atualizações de cartografia geológica inéditas feitas por Steiner e Roldan (2007).

Foram utilizadas neste trabalho as cenas do satélite Landsat-TM, fornecidas gratuitamente pelo (Instituto Nacional de Pesquisas Espaciais - INPE), e o Modelo Digital de Elevação (MDE) da missão espacial SRTM , disponíveis gratuitamente no link http://seamless.usgs. gov, com resolução espacial de $90 \mathrm{~m}$. A imagem de satélite usada corresponde à cena 221/79, de 12 de outubro de 2002 (azimute solar 41,1 g e inclinação solar 34,1 g), banda 8 , pancromática, com resolução espacial de $15 \mathrm{~m}$. Para realçar as estruturas lineares foram utilizados filtros "passa alta". O pré-processamento da imagem incluiu a correção atmosférica, visando eliminar o efeito da reflectância dos objetos ou alvos registrados pelos sensores, em função das interferências produzidas por moléculas de gases da atmosfera (Turner et al., 1971). Com o objetivo de eliminar esses efeitos foi utilizado o método da subtração, também conhecido como o método do pixel escuro, segundo calibração descrita por Chavez (1988).

A partir do Modelo Digital de Elevação (MDE-SRTM) da NASA, com resolução espacial de $90 \mathrm{~m}$, foi realizada a reamostragem do MDE para 30 $\mathrm{m}$ da área investigada. Para uma análise mais detalhada utilizou-se o método de reamostragem Short Distance-Low Nugger Kriging (SDLN), com interpolação por médias móveis, segundo Grohmann \& Steiner (2006), aumentando, com isso, a definição do modelo. Em seguida, foram geradas as imagens de relevo sombreado em oito direções diferentes de iluminantes (N, S, E, W, NE, SE, SW e NW), todas posicionadas com ângulo de elevação solar a $35^{\circ}$, com o intuito de realçar os lineamentos ortogonais e oblíquos aos mesmos. Para esse procedimento, utilizou-se o software ENVI. Os melhores resultados foram obtidos com os iluminantes orientados nas posições N, E, NE e NW, os quais utilizaram-se para extração dos lineamentos. Nas imagens de relevo sombreado foram feitas composições coloridas (RGB), seguindo os procedimentos descritos por Crepani \& Medeiros (2004).

Fotolineamentos $\mathrm{O}$ termo lineamento foi usado de acordo com O'Leary et al. (1976), que o consideram 
uma feição de expressão regional mapeável na superfície terrestre de forma linear, retilínea ou suavemente encurvada, simples ou composta. A sua presença reflete fenômenos de subsuperfície que podem estar relacionados a falhas, fraturas ou outras morfoestruturas. Os lineamentos podem representar altos topográficos (lineamentos positivos, como cristas alinhadas) e baixos topográficos (lineamentos negativos, como drenagens e vales).

Considerou-se ainda a proposta de Strieder \& Amaro (1997), que dividem os lineamentos em dois tipos: 1 e 2. O primeiro é associado a estruturas penetrativas, tais como foliação, xistosidade e acamamento. E o segundo é associado geralmente a estruturas rúpteis, expressas por feições como drenagens retilíneas e vales encaixados.

A análise dos fotolineamentos foi realizada segundo o método multiescala (ao redor de 1:50.000 e menor do que 1:300.000) e a sua extração foi feita por meio da interpretação visual das imagens (Landsat-TM e MDE-SRTM) na tela do computador.

Os resultados obtidos pelos dois métodos foram integrados e são aqui apresentados numa mesma imagem, com os fotolineamentos sendo mostrados de forma estatística em diagramas de roseta, considerando o seu comprimento e a frequência.

Análise estrutural A análise estrutural foi realizada a partir do levantamento de falhas e estrias de duas pedreiras situadas no interior do Domo de Lages: uma delas na parte Sul da estrutura (pedreira Porto Belo) e a outra na parte Norte (pedreira Rio do Deserto).

Nestas pedreiras foram analisadas a geometria e cinemática das diferentes famílias de falhas, seguindo os procedimentos descritos e sumarizados em diversos trabalhos e livros, como os de Mercier \& Vergeley (1992), Vialon et al. (1976), Petit (1987), Doblas (1998), dentre outros. Tomou-se o cuidado de separar as falhas preenchidas e analisou-se o crescimento mineral, sintaxial ou antitaxial (Petit 1987, Doblas 1998).

Os dados estruturais obtidos são apresentados em diagramas de projeção ciclográfica SchmidtLambert, com os elementos estruturais projetados no hemisfério inferior. Eles foram, inicialmente, sistematizados em planilhas digitais (Excel) e separados por famílias de falhas. Depois geraram-se os estereogramas usando os programas TectonicsFP (Reiter \& Acs 1995) e OpenStereo (Grohmann \& Campanha 2010), este disponível gratuitamente para download.

\section{RESULTADOS}

Fotolineamentos $\mathrm{O}$ mapa de fotolineamentos obtido (Fig. 3A) evidencia feições lineares principais orientadas próximas de N-S e NW (N30-45W) e, secundariamente, ao redor de N15E e N80E. As feições lineares N-S são penetrativas no domo, sendo caracterizadas por traços curtos e retilíneos, rigorosamente paralelos entre si, exibindo, sobretudo na parte central da área, um padrão de estruturas em relay (traços mais curtos paralelos a mais longos). As feições lineares NW correspondem a lineamentos no sentido de O'Leary et al. (1976). São marcadas por traços longos e mais ou menos contínuos, subparalelos e espaçados, sendo mais expressivos na porção Centro-Sudeste da área (Fig. 3A).

As feições lineares ao redor de N15E, presentes particularmente na extremidade Sul da área, são marcadas por traços curtos e retilíneos, sendo truncadas aparentemente pelas estruturas NW (Fig. 3A). Já as estruturas próximas de $\mathrm{N} 80 \mathrm{E}$, mais expressivas na parte Sul da área, mostram um padrão de traços mais longos e descontínuos, que truncam aparentemente os padrões N-S e N15E.

Os lineamentos em diagramas de roseta mostram distribuição semelhante em comprimento e frequência, com máximos ao redor de N-S, sendo este melhor expresso no diagrama de frequência, NNW (N20-30W) e NW (N40-50W) (Figs. 3B e C). A análise regional desses lineamentos, apenas em termos de comprimento, evidencia duas direções principais: N40-50W e N60-70E (Fig. 3B), que correspondem a lineamentos com extensão de ordem quilométrica na imagem (>18 km).

Análise estrutural A Fig. 4A mostra os dados estruturais obtidos na pedreira Porto Belo (301 medidas). Os dados foram separados em dois grupos: um com 141 medidas que apresentava indicador cinemático (estrias com estepes, crescimento de fibras e, mais raramente, estruturas 'R') no plano de falha; e outro com 201 medidas, no qual este indicador não foi observado ou era de confiabilidade baixa. Apesar da dispersão dos dados nos estereogramas, é possível reconhecer os seguintes padrões de direções de falhas: NE-SW, NNE-SSW, N-S e E-W (ENE-WSW a ESE-WNW). Os três primeiros padrões de falhas são igualmente representados no diagrama de roseta (Figs. 3B e C). São falhas em geral de alto ângulo, exceto as de direção NE-SW que apresentam mergulhos moderados para NW e SE. A relação das estrias com o plano de falha evidencia a presença de falhas transcorrentes (destral e sinistral), normais e oblíquas. As primeiras ocorrem nas 

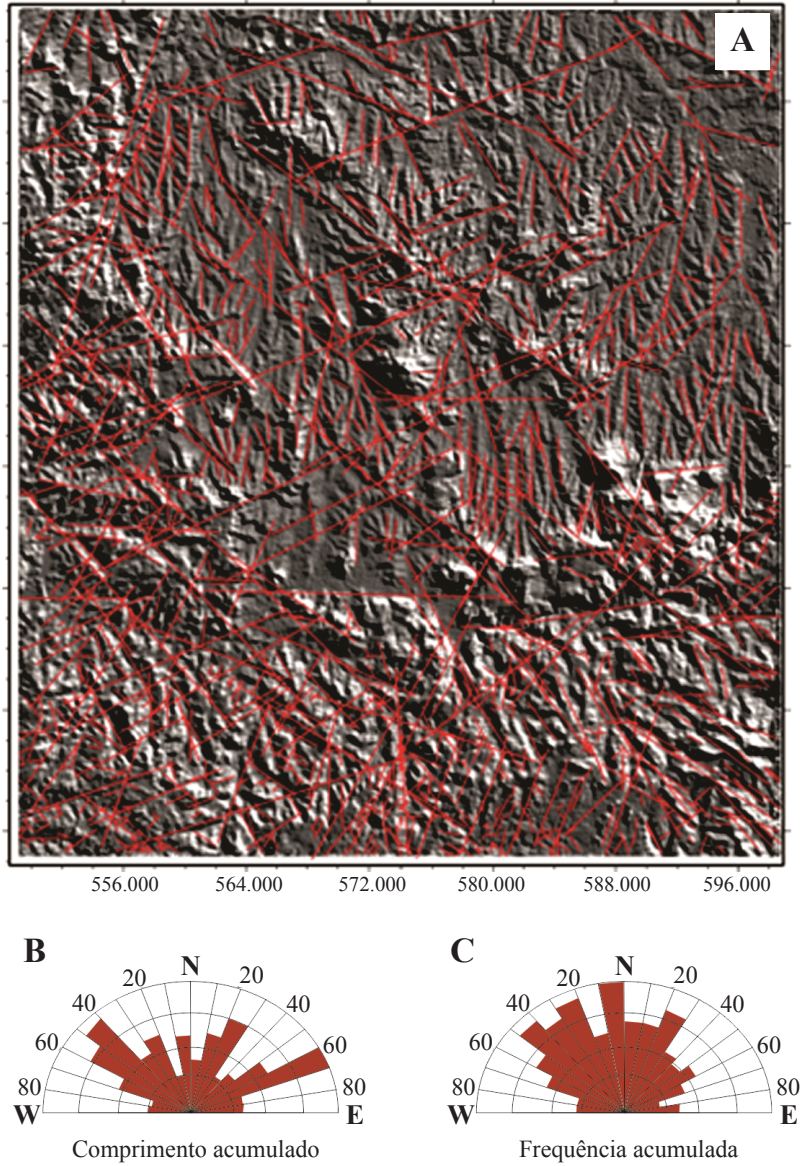

Figura 3 - Mapa com a somatória dos lineamentos extraídos dos mapas de relevo sombreado e da imagem de satélite (A) e diagramas de roseta de comprimento e frequência acumulados ( $B$ e $C$ ).

quatro direções acima, e as duas últimas são mais comuns na direção NE-SW.

A Fig. 4B apresenta os dados estruturais obtidos na pedreira Rio do Deserto (201 medidas). Assim como na pedreira anterior, os dados foram separados em dois grupos: um (60 medidas) com o indicador cinemático no plano de falha e outro (141 medidas) no qual o indicador não foi observado ou era de confiabilidade baixa.

A análise integrada dos dados em projeção ciclográfica evidencia três padrões principais de falhas transcorrentes: ENE-WSW, N-S/NNE-SSW e, subordinadamente, NE-SW. Tais padrões aparecem também no diagrama de roseta (Figs. 3B e C). O primeiro apresenta cinemática sinistral, e os dois últimos, destral. Ao padrão N-S/NNE-SSW associam-se também falhas oblíquas e, subordinadamente, falhas normais (Fig. 4B).

DISCUSSÃO Os fotolineamentos com direções ao redor de N-S, NNE, NW e ENE acham-se também representados nos diagramas das duas pedreiras (Figs. 4A e
B). As estruturas NE, claramente evidenciadas na pedreira Porto Belo, aparecem como secundárias nos diagramas de roseta de comprimento e frequência acumulados (Figs. 3B e C). Este diagrama realça melhor os fotolineamentos N-S, N20-30W e N40-50W.

As duas direções de falhas transcorrentes $(\mathrm{N}-\mathrm{S}$, destral, e ESE-WSW, sinistral) da pedreira Porto Belo são compatíveis com um mesmo campo de esforço com eixo de tensão máximo $\left(\sigma_{1}\right)$ ao redor de NE-SW, conforme já sugerido por Roldan (2007). $\mathrm{O}$ baixo caimento das estrias (em geral, $<10^{\circ}$ ) sugere $\left(\sigma_{1}\right)$ em posição sub-horizontal. Este evento tectônico é posterior à colocação das rochas alcalinas, de idade $(\mathrm{K} /$ $\mathrm{Ar}, \mathrm{Rb} / \mathrm{Sr}, \mathrm{Ar} / \mathrm{Ar}$ ) ao redor de $75 \mathrm{Ma}$ (Scheibe et al. 1985, Machado \& Teixeira 2008).

As falhas normais NE-SW sugerem mudanças no campo de tensão e podem estar associadas ao colapso da estrutura dômica, uma vez que mostram mergulhos altos e moderados, respectivamente para NW e SE, e associam-se à falhas oblíquas com componente distensional. Estas falhas parecem reativar estruturas pré-existentes da bacia e do seu embasamento (Fig. 1). São reportadas na região de Lages falhas reativadas no Plioceno que cortam as bauxitas (Dani 1998, Dani et al. 2001).

As falhas transcorrentes N-S a N-NE (destral) e ENE-WSW (sinistral) da pedreira Rio do Deserto podem ser explicadas segundo o mesmo campo de tensão das transcorrências da pedreira anterior. Aqui ocorrem também falhas normais NE-SW com mergulhos moderados para NW e SE, sugerindo extensão nestas duas direções.

O campo de tensão NE-SW é compatível com a direção dominante (NE-SW) de diques alcalinos e de lamprófiros, cartografados no domo (em Roldan 2007), cujo magma teria sido alojado ao longo de fraturas $\mathrm{T}$, segundo o modelo de Riedel (Roldan 2007). Exposições destas rochas são encontradas em Lages e arredores, como na pedreira Morro Grande, ao Sul da cidade, ena rodoviaLagesSão José do Cerrito (BR-262), localidade de Boqueirão, em um corte próximo ao trevo $(\sim 1 \mathrm{~km})$ com a BR-116. Um evento distensivo mais novo NW-SE reativa as transcorrências anteriores como falhas normais NE-SW, e diques de rochas alcalinas reaproveitam tais estruturas (Roldan 2007).

As transcorrências aqui discutidas são compatíveis, em termos cinemáticos e campos de tensão, com as estruturas descritas no distrito fluorítico de Santa Catarina por Ferreira \& Almeida (1989). Tratam-se de falhas transcorrentes destrais N0-10E e sinistrais N50$60 \mathrm{E}$, identificadas, respectivamente, como estruturas R e 


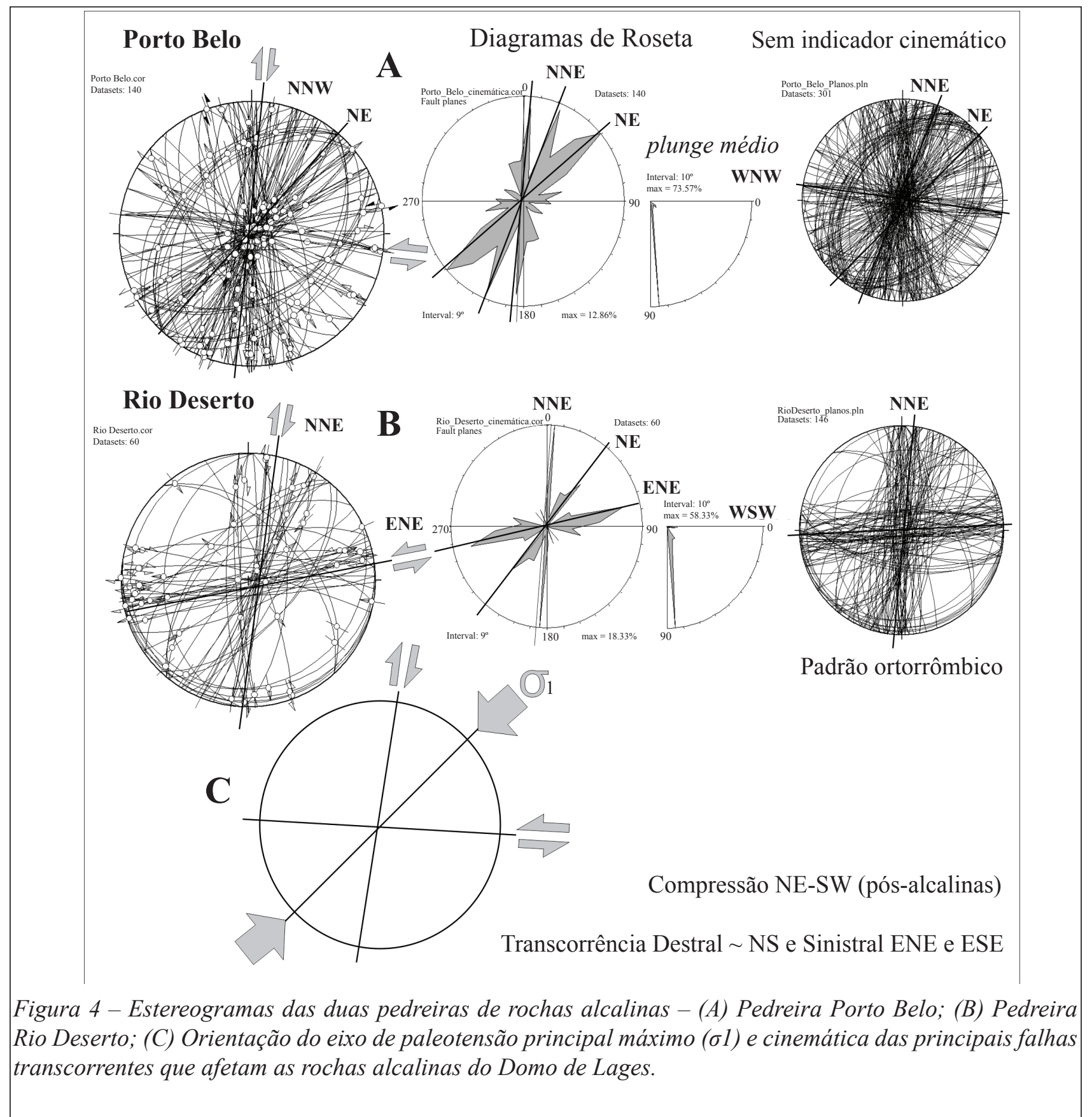

R'de Riedel e normais N20-40E (mineralizadas ou não), relacionadas, respectivamente, a eventos compressivos (regime transtensivo) e distensivos (mais novo). Tais falhas são estruturas reativadas durante o Mesozoico.

O campo de tensão aqui sugerido é similar ao das transcorrências WSW-ENE da fase deformacional $D_{2}$, provavelmente de mesma idade, descritas no Arco de Ponta Grossa, no Sul do Paraná e Norte de Santa Catarina (Strugale et al. 2003 e 2007, Freitas \& Rostirolla 2005).

A tectônica transcorrente aqui descrita é registrada em altos estruturais da Bacia do Paraná (Quatiguá, no Paraná, e Pitanga, em São Paulo) e nas bacias terciárias associadas ao Rift Continental do Sudeste do Brasil, com idade entre o Cretáceo Superior e o Neógeno (Mioceno?) (Riccomini 1989, 1995a, 1995b, Riccomini et al. 2004, Rostirolla et al. 2000). As falhas transcorrentes N40-60E, associadas ao Alto Estrutural de Quatiguá, de caráter inicialmente sinistral e depois destral, foram relacionadas à reativação de falhas do embasamento (Zona de Falha de Jacutinga) na cobertura paleozoica da bacia (Rostirolla et al. 2000). Falhas transcorrentes sinistrais N-NW e NW foram descritas no Alto Estrutural de Pitanga, em São Paulo (Riccomini 1995a).

As estruturas discutidas neste trabalho têm orientação similar à do embasamento que contorna a borda da bacia no Sul do Brasil - escudos catarinense, paranaense e sul-rio-grandense - em particular os padrões NNE e NE, que representam zonas de fraqueza antigas reativadas que controlaram a formação de falhas mais 
novas (Zalán et al. 1987, 1990, Ferreira \& Almeida 1989, Almeida 2005, Roldan et al. 2010). Estas mesmas direções estruturais foram registradas em outras regiões da bacia, afetando os sedimentos fanerozoicos, conforme sugerem os dados geofísicos (Milani 1997, Rostirolla et al. 2000, Freitas \& Rostirolla 2005, dentre outros).

CONSIDERAÇÕES FINAIS Os dados aqui apresentados evidenciam correlação entre os fotolineamentos obtidos a partir das imagens integradas (Landsat-TM e SRTM) e as falhas analisadas nas pedreiras de rochas alcalinas, em particular as estruturas ao redor de N-S (NNE a NNW), ENE e, secundariamente, NE e NW. As direções N-S são realçadas no diagrama de frequência acumulada, e as direções NW e ENE, no diagrama de comprimento acumulado.

As transcorrências caracterizadas neste trabalho — destral com direção ao redor de N-S (NNW a NNE), e sinistral com orientação próxima de E-W (ENE a ESE), juntamente com a orientação dominante NE-SW dos diques de lamprófiro e de rocha alcalina presentes na região domo - são compatíveis com um evento compressivo com eixo de tensão principal máximo $\left(\sigma_{1}\right)$ orientado ao redor de NE-SW (Fig. 4C). Tais falhas são zonas de fraqueza antigas da bacia e do seu embasamento que foram reativadas após e provavelmente durante a colocação dos lamprófiros e das rochas alcalinas.

As transcorrências de Lages são, certamente, mais novas do que as rochas alcalinas ( $75 \mathrm{Ma})$, com idade entre o Neocretáceo e o Terciário. No entanto, o evento que originou tais estruturas poderia estar ativo um pouco antes das falhas e ter sido também responsável pela estruturação do Domo de Lages.

As falhas aqui discutidas são semelhantes (em orientação, cinemática e, provavelmente, em idade) às transcorrências destrais N0-10E e sinistrais N50-60E definidas no distrito fluorítico de Santa Catarina.

O campo de tensão definido neste trabalho é compatível com o das transcorrências sinistrais E-W de idade paleocênica/eocênica ou neogênica (Mioceno?), que afetaram o Maciço Alcalino de Cananeia e controlaram a instalação de bacias de afastamento de pequenas dimensões (Formação Itaquaquecetuba), bem como responderam pela geração de dobras cônicas na Bacia de Taubaté (Riccomini 1989, 1995a, Riccomini et al. 2004). Este evento precederia ao de distensão crustal com direção NNWSSE, responsável pela instalação das bacias tectônicas do Rift Continental do Sudeste do Brasil, com idade do Paleógeno (Eoceno-Oligoceno) (Riccomini 1989, 1995b, Riccomini et al. 2004).

Este campo de tensão assemelha-se ao das transcorrências mais novas da Bacia do Camaquã, embora a idade lá seja considerada mais antiga, do Triássico (Almeida 2005). A fase deformacional (ou evento) - D2, caracterizada no Arco de Ponta Grossa e Sul do Paraná com o Norte de Santa Catarina, tem idade similar (Cretáceo ao Terciário) à definida para a região de Lages, diferindo quanto à orientação $(20 \mathrm{a}$ $40^{\circ}$ no sentido horário) do eixo do campo de tensão principal $\left(\sigma_{1}\right)$. Tais variações do campo de tensão regional podem relacionar-se com a partição da deformação induzida por heterogeneidades das estruturas do embasamento (falhas e zonas de cisalhamento anastomosadas, interferência de outras direções estruturais, descontinuidades, arcos e flexuras do embasamento, etc.), combinada com o movimento de rotação da placa Sul-Americana para Oeste.

O Domo de Lages está inserido no contexto tectônico de estruturas regionais NW reativadas na borda Leste da Bacia do Paraná no Juro-Cretáceo, a exemplo do Arco de Ponta Grossa, que condicionou a colocação de diques básicos ligados à Formação Serra Geral. No entanto, o referido domo se constitui numa estrutura NW de reativação mais nova, nucleada somente no Neocretáceo.

A atividade tectônica da Bacia do Paraná, no Mesozoico e Cenozoico, tem sido considerada em parte como o reflexo, no interior da placa Sul-Americana, de fenômenos ocorridos às suas bordas: a Oeste com a subducção da Placa de Nazca, e a Leste, com a abertura do Oceano Atlântico Sul, expansão da Dorsal MesoAtlântica e migração da placa Sul-Americana para Oeste (Riccomini 1989, 1995b, Riccomini et al. 2004). Portanto, é neste contexto geodinâmico geral que se insere o Domo de Lages - estruturação, magmatismo alcalino e tectônica transcorrente - e estruturas similares de mesma idade (Neocretáceo/Terciário) associadas à borda Leste da Bacia do Paraná, no Sul do Brasil. Contudo, outros aspectos devem ter contribuído para o desenvolvimento das transcorrências aqui estudadas, pois, em termos mecânicos, torna-se difícil, com uma tensão compressiva horizontal E-W, considerada para a Placa Sul-Americana durante o Cenozoico (Assumpção 1992, Lima et al. 1997), ativar (ou reativar) lineamentos subortogonais com orientação próxima de N-S, a não ser que isso ocorra em um sistema com partição de deformação relativamente complexo. 
AGRADECIMENTOS Os autores externam seus agradecimentos à Prefeitura Municipal de Lages (SC) pelo apoio de infraestrutura fornecido para o desenvolvimento das atividades de campo, bem como ao Conselho Nacional de Desenvolvimento Científico e Tecnológico
(CNPq), processo 300423/82-9, de R. Machado, pela concessão de uma bolsa de Produtividade em Pesquisa, e à Coordenação de Aperfeiçoamento de Pessoal de Nível Superior (CAPES), por uma bolsa de doutorado.

\section{Referências}

Almeida F.F.M. 1967. Origem e evolução da plataforma brasileira. Rio de Janeiro, DNPM/DGM, Boletim 241, $36 \mathrm{p}$.

Almeida F.F.M. 1983. Relações tectônicas das rochas alcalinas mesozóicas da região meridional da plataforma SulAmericana. Revista Brasileira de Geociências, 13(3):139158.

Almeida F.F.M. 1986. Distribuição regional e relações tectônicas do magmatismo pós-Paleozóico no Brasil. Revista Brasileira de Geociências, 16(4):325-349.

Almeida F.F.M. 2000. Síntese sobre a tectônica da Bacia do Paraná. In: SBG, Simp. Reg. Geol., 3, Curitiba, PR, Atas, v. 1, p. 1-20.

Almeida R.P. 2005. Tectônica e sedimentação do Ediacarano ao Ordoviciano: exemplos do Supergrupo Camaquã (RS) e do Grupo Caacupé (Paraguai Oriental). Tese de Doutorado, Instituto de Geociências, Universidade de São Paulo, São Paulo, 203 p.

Almeida R.P., Janikian L., Fragoso-Cesar A.R.S, Fambrini G.L. 2010. The Ediacaran to Cambrian rift system of Southeastern South America: tectonic Implications. Journal of Geology, 118:145-161.

Assumpção M. 1992. The regional intraplate stress field in South America. Journal of Geophysical Research, 97:11889-11903.

Chavez P.S. 1988. An improved dark-object subtraction technique for atmospheric scattering correction of multispectral data. Remote Sensing of Environment, 24:459-479.

Barabino G., Gomes C.B., Traversa G. 2007. The Lages diatremes: mineral composition and petrological implications. Anais da Academia Brasileira de Ciências, 79(3):473-501.

Barbosa O. 1933. Eruptivas de Lages, Santa Catarina. Ministério daAgricultura, Serviço Geológico Mineralógico, Boletim 69, p. 15-18.

Basei M.A.S., Siga Jr. O., Masquelin H., Harara O.M., Reis Neto J.M., Preciozzi P.F. 2000. The Dom Feliciano Belt and Rio de la Plata Craton: tectonic evolution and correlation with similar provinces of southwestern Africa. In: Cordani U.G, Milani E.J., Thomas Filho A., Campos D.A., Intern. Geol. Congr., 31, Rio de Janeiro, Tectonic evolution of South America, p. 311-334.

Bitencourt M.F. 1996. Granitóides sintectônicos da região de Porto Belo, SC: Uma abordagem petrológica e estrutural do magmatismo em zonas de cisalhamento. Tese de
Doutorado, Instituto de Geociências, Universidade Federal do Rio Grande do Sul, Porto Alegre, $310 \mathrm{p}$.

Bitencourt M.F. \& Nardi L.V.S. 2000. Tectonic setting and sources of magmatism related to the Southern Brazilian Shear Belt. Revista Brasileira de Geociências, 30(1):184187.

Bitencourt M.F., Bongiolo E.M., Philipp R.P., Morales L.F.G., Rubert R.R., Melo C.L., Luft J.L. 2008. Estratigrafia do Batólito Florianópolis, Cinturão Dom Feliciano, na região de Garopaba-Paulo Lopes, SC. Pesquisas em Geociências, 35(1):109-136.

Comin-Chiaramonti P., Gomes C.B., Castorina F., Di Censi P., Antonini P., Ruberti E., Scheibe L.F. 2002. Geochemistry and geodynamic implications of the Anitápolis and Lages alkaline-carbonatite complexes, Santa Catarina State. Revista Brasileira de Geoociências, 32(1):43-58.

Cordani U.G. \& Vandoros P. 1967. Basaltic rocks of the Paraná basin. In: Bigarella J.J., Pinto I.D., Becker R.D. Problems in Brazilian Gondwana Geology. Curitiba, UFPR, p. 207229.

Crepani E. \& Medeiros J.S. 2004. Imagens fotográficas derivadas de MNT do projeto SRTM para fotointerpretação na Geologia, Geomorfologia e Pedologia. São José dos Campos, Inpe, 39 p. Dani N. 1998. Petrologia das alterações pós-magmáticas e meteóricas das rochas alcalinas de Lages, SC - Brasil. Tese de Doutorado. Instituto de Geociências, Universidade Federal do Rio Grande do Sul, Porto Alegre, 228 p.

Dani N., Formoso M.L.L., Lisboa N.A. 2001. Evolução da Plataforma Sul-Brasileira e o posicionamento estratigráfico da bauxita de Lages, SC, Brasil. In: Congr. Latinoamer. Geol., 11, v. 1, p. 45.

Doblas M. 1998. Slikenside kinematic indicators. Tectonophyics, 295(1-2):187-197.

Ferreira A.C. \& Almeida T.I.R. 1989. Tectônica transcorrente e imagens. TM-Landsat aplicadas à prospecção de fluorita e barita em Santa Catarina. Revista de Brasileira de Geociências, 19(2):207-223.

Ferreira F.J.F. 1982. Integração de dados aeromagnéticos e geológicos: configuração e evolução tectônica do Arco de Ponta Grossa. Dissertação de Mestrado. Instituto de Geociências, Universidade de São Paulo, São Paulo, 170 p.

Freitas M.A., Caye B.R., Machado J.L.F. 2002. Diagnóstico dos recursos hídricos subterrâneos do oeste do Estado de Santa Catarina - Projeto Oeste de Santa Catarina. Porto Alegre, CPRM/SDM-SC/SDA-SC/EPAGRI, 100 p. 
Freitas R.C. 2005. Análise estrutural multitemática do sistema petrolifero Irati-Rio Bonito, Bacia do Paraná. Dissertação de Mestrado. Instituto de Geociências, Universidade Federal do Paraná, Curitiba, 98 p.

Freitas R.C. \& Rostirolla S.P. 2005. Análise comparativa entre estruturas do embasamento e resposta em superfície na Bacia do Paraná, região entre os Estados do Paraná e Santa Catarina. In: SBG, Simp. Nac. de Estudos Tectônicos, 10; Int. Symp. on Tectonics, 4, Curitiba, Boletim de Resumos Expandidos, v. 1, p. 41-44.

Fúlfaro V.J. 1971. Evolução tectônica e paleogeográfica da bacia sedimentar do Paraná pelo "Trend surfasse analysis". Tese de Doutorado. Instituto de Geociências, Universidade de São Paulo, São Paulo, 224 p.

Furtado S.M.A. \& Scheibe L.F. 1989. Ocorrências de lamprófiros associados aos distritos alcalinos de Lages e Anitápolis. Geochimica Brasiliense, 3:149-160.

Grohmann C.H. \& Campanha G.A.C. 2010. OpenStereo: open source, cross-platform software for structural geology analysis. Instituto de Geociências, Universidade de São Paulo, São Paulo, xx. Abstract presented at 2010 Fall Meeting, American Geophysical Union (AGU), San Francisco, Califórnia, EUA, 13-17 Dec.

Grohmann C.H. \& Steiner S.S. 2006. SRTM resample with Short Distance-Low Nugget Kriging. In: Proceedings of International Symposium on Terrain Analysis and Digital Terrain Modelling. Nanjing, China, editor, CD-Rom.

Instituto de Pesquisas Tecnológicas do Estado de São Paulo. 1980. Tectônica da Bacia do Paraná no Brasil. São Paulo, IPT, Relatório Técnico 91, 187 p.

Jacques P., Machado R., Nummer A. 2010. Lineamentos estruturais na borda leste da Bacia do Paraná em Santa Catarina: análise multiescala com base em imagens Landsat e SRTM. Pesquisas em Geociências 37(2):117-131.

Lima C., Nascimento E., Assumpção M. 1997. Stress orientations in Brazilian sedimentary basins from breakout analysis: implications for force models in the South American plate. Geophysical Journal International, 130(1):112-124.

Loczy L. 1966. Evolução paleogeográfica e geotectônica da Bacia Gondwânica do Paraná e seu embasamento. Rio de Janeiro, DNPM/DGM, 234 p.

Loczy L. 1968. Basic and alkalic volcanics of the State of Santa Catarina. Anais da Academia Brasileira de Ciências, 40:187-193.

Milani E.J. 1997. Evolução tectono-estratigráfica da Bacia do Paraná e seu relacionamento com a geodinâmica fanerozóica do Gonduana Sul-Ocidental. Tese de Doutorado. Instituto de Geociências, Universidade Federal do Rio Grande do Sul, Porto Alegre, 225 p.

Milani E.J. 2004. Comentários sobre a origem e a evolução da Bacia do Paraná. In: Mantenesso-Net V., Bartorelli A., Carneiro C.D.R. Neves B.B.B. (eds.) Geologia do Continente Sul-Americano: a evolução da obra de Fernando Flávio Marques de Almeida. In: Mantesso-Neto V., Bartorelli A., Carneiro C.D.R., Neves B.B.B. (eds). Ed. Beca, São Paulo, p.265-279.

Milani E.J. \& Ramos V. 1998. Orogenias paleozóicas no domínio sul-ocidental do Gondwana e os ciclos de subsidência da Bacia do Paraná. Revista Brasileira Geociências, 28(4):473-484.

Milani E.J. \& Thomaz Filho A. 2000. Sedimentary basins of the South America. In: Cordani U.G., Milani E.J., Thomaz Filho A., Campos D.A. (eds.) Tectonic Evolution of South America. Rio de Janeiro, International Geological Congress, 31, p. 389-449.

Milani E.J., Melo J.H.G., Souza P.A., Fernandes L.A., França A.B. 2007. Bacia do Paraná. Boletim de Geociências da Petrobras, 15(2):265-287.

Machado F.G. \& Rostirolla S.P. 2005. Caracterização estrutural preliminar da área de Jaguariaíva, Bacia do Paraná. In: SBG, Simp. Nac. de Estudos Tectônicos, 10, Int. Symp. on Tectonics, 4, Curitiba, Boletim de Resumos Expandidos, p. 38-40.

Machado R. \& Teixeira W. 2008. Idades $\left({ }^{40} \mathrm{Ar} /{ }^{39} \mathrm{Ar}\right)$ do Magmatismo Alcalino do Distrito Alcalino de Lages, SC. In: SBG, Simp. Vulc. e Amb. Assoc., 4, Boletim de Resumos. CD-Rom.

Mercier J. \& Vergely P. 1992. Tectonique. Paris, Dunod, 214 p.

Mezzomo E. \& Rostirolla S.P. 2005. Delimitação do arcabouço estrutural na porção centro leste do Paraná, Bacia do Paraná, com base na análise de sensores remotos, estudos de campo e modelagem estrutural tridimensional. In: SBG, Simp. Nac. de Estudos Tectônicos, 10, Int. Symp. on Tectonics, 4, Boletim de Resumos Expandidos, p. 35-39.

Northfleet A.A., Medeiros R.A., Mülhmann H. 1969. Reavaliação dos dados geológicos da Bacia do Paraná. Boletim Técnico da Petrobrás, 12(3):291-346.

O’Leary D.W., Friedman J.D., Pohn H.A. 1976. Lineament, linear, lineation: some proposed new standards for old terms. Geological Society of America Bulletin, 87:14631469.

Paiva T.G. 1933. Geologia do municipio de Lages, Santa Catarina. Ministério da Agricultura, Serviço Geológico Mineralógico, Boletim 69, p. 3-14.

Passarelli C.R. 1996. Análise estrutural e caracterização do magmatismo da zona de cisalhamento Major Gercino, SC. Dissertação de Mestrado. Instituto de Geociências, Universidade de São Paulo, São Paulo, 178 p.

Petit J.P. 1987. Criteria for the sense of movement on fault surfaces in brittle rocks. Journal of Structural Geology, 9(5-6):597-608.

Ramos V.A., Jordan T.E., Allmendinger R.W., Kay S.M., Cortes J.M., Palma M. 1986. Paleozoic terranes of the central Argentine-Chilean Andes. Tectonics, 5(6):855-880.

Reiter F.G. \& Acs P. 1995. Programa demo para tratamento de dados estruturais. Disponível em www.uibk.ac.at/ homepage/Franz.Reiter, consultado acessado em 08/02/2012.

Riccomini C. 1989. O Rift Continental do Sudeste do Brasil. Tese de Doutoramento, Instituto de Geociências, Universidade de São Paulo, São Paulo, 256 p.

Riccomini C. 1995a. Tectonismo gerador e deformador dos depósitos sedimentares pós-Gondwânicos da porção centro-oriental do Estado de São Paulo e áreas vizinhas. 
Tese de Livre-Docência. Instituto de Geociências, Universidade de São Paulo, São Paulo, 100 p.

Riccomini C. 1995b. Padrão de fraturamentos do maciço alcalino de Cananéia, Estado de São Paulo: relações com a tectônica mesozóica-cenozóica do sudeste do Brasil. Revista Brasileira de Geociências, 25(2):79-84.

Riccomini C., Sant'Anna L.G., Ferrari A.L. 2004. Evolução geológica do Rift Continental do Sudeste do Brasil. In: Mantesso-Neto V., Bartorelli A., Carneiro C.D.R., Brito Neves B.B. (orgs.) Geologia do Continente Sul-Americano: evolução da obra de Fernando Flávio Marques de Almeida. São Paulo, Editora Beca, p. 383-405.

Roldan L.F. 2007. Tectônica rúptil Meso-Cenozóica na região do Domo de Lages, SC. Dissertação de Mestrado. Instituto de Geociências, Universidade de São Paulo, São Paulo, $121 \mathrm{p}$.

Roldan L.F., Machado R., Steiner S.S., Warren L.V. 2010. Análise de lineamentos estruturais no Domo de Lages (SC) com uso de imagens de satélite e mapas de relevo sombreado. Geologia USP, 10(2):57-72.

Rostirolla S.P., Assine M.L., Fernandes L.A, Artur P.C. 2000. Reativação de paleolineamentos durante a evolução da Bacia do Paraná - o exemplo do alto estrutural de Quatiguá. Revista Brasileira de Geociências, 30(4):639-648.

Scheibe L.F. 1980. Distrito alcalino de Lages-SC. In: SBG, Congr. Bras. Geol., 31, Boletim de Resumos Expandidos, vol. 3, p. 25-31.

Scheibe L.F. 1986. Geologia e petrologia do distrito alcalino de Lages, SC. Tese de Doutorado, Instituto de Geociências, Universidade de São Paulo, São Paulo, 224 p.

Scheibe L.F., Kawashita K., Gomes C.B. 1985. Contribuição à geocronologia do Complexo Alcalino de Lages, SC. In: SBG, Simp. Sul-Bras. Geol., 2, Anais, p. 299-307.

Schneider R.L., Mühlmann H., Tommasi E., Medeiros R.A., Daemon R.F., Nogueira A.A. 1974. Revisão estratigráfica da Bacia do Paraná. In: SBG, Congr. Bras. Geol., 28, Anais, v. 1, p. 41-65.

Schobbenhaus C., Campos D.A., Derze G.R., Asmus H.E. 1984. Geologia do Brasil: texto explicativo do mapa geológico do Brasil e área oceânica adjacente incluindo depósitos minerais. Brasília, DNPM-MME, 501 p.

Scorza E.P. 1937. Olivinamelilitito - uma rocha rara e até agora desconhecida no Brasil continental. Engenharia, Mineração e Metalurgia, XLII (252):235-237.

Soares P.C., Barcellos P.E., Csordas S.M. 1982. Análise, interpretação e integração de lineamentos a partir de imagens (Radar-Landsat) e suas relações com a tectônica da Bacia do Paraná. São Paulo, Paulipetro, Consórcio CESP/IPT, Relatório RT-342/82.

Soares P.C., Rostirolla S.P., Ferreira F.J.F., Stevanato R. 1996. $\mathrm{O}$ alto estrutural Pitanga-Quatiguá-Jacutinga na Bacia do Paraná: uma estrutura litosférica. In: SBG, Congr. Bras. Geol., 39, Anais, 5:411-414.

Soares P.C. 1976. Elementos estruturais da parte NE da Bacia do Paraná: classificação de gênese. In: SBG, Congr. Bras. Geol., 28, Anais, 1:107-121.

Souza M.O.L. 1997. Caracterização estrutural do Domo de
Pitanga. Dissertação de Mestrado, Instituto de Geociências e Ciências Exatas, Universidade Estadual Paulista, Rio Claro, $116 \mathrm{p}$.

Souza M.O.L. 2002. Evolução tectônica dos altos estruturais de Pitanga, Artemis, Pau D’Alho e Jibóia - Centro do Estado de São Paulo. Tese de Doutoramento, Instituto de Geociências e Ciências Exatas, Universidade Estadual Paulista, Rio Claro, 206 p.

Strieder A.J. \& Amaro V.E. 1997. Structural patterns removed from remotely sensed lineaments. Revista da Escola de Engenharia, 25(4):109-117.

Strugale M. 2002. Arcabouço e evolução estrutural do Arco de Ponta Grossa no Grupo São Bento (Mesozóico): implicações na hidrodinâmica do Sistema Aqüifero Guarani e na migração de hidrocarbonetos na Bacia do Paraná. Dissertação de Mestrado. Instituto de Geologia, Universidade Federal do Paraná, Curitiba, 154 p.

Strugale M., Rostirolla S.P., Kulevicz M.B., Mancini F.. 2003. Evolução estrutural do Arco de Ponta Grossa no Cretáceo a partir da análise de estruturas rúpteis no Grupo São Bento (Bacia do Paraná). In: Simp. Nac. Est. Tect., 9, Boletim de Resumos, p. 320-323.

Strugale M., Rostirolla S.P., Mancini F., Portela Filho C.V., Ferreira F.J.F.. Freitas R.C. 2007. Structural framework and Mesozoic-Cenozoic evolution of Ponta Grossa Arch, Paraná Basin, southern Brazil. Journal of South American Earth Sciences, 24:203-227.

Traversa G., Schelbe L.F., Barbieri M., Beccaluva L., Coltorti M, Conte A.M., Garbarino C., Gomes C.B., Macciotta G, Morbidelli L., Ronca S. 1994. Petrology and mineral chemistry of the alkaline district of Lages, SC, Brazil. Geochimica Brasiliensis, 8:179-214.

Traversa G., Barbieri M., Beccaluva L., Coltorti M., Conte A.M., Garbarino C., Gomes C.B., Macciotta G., Morbidelli L., Ronca S., Scheibe L.F. 1996. Mantle sources and differentiation of alkaline magmatic suite of Lages, SC, Brazil. Eur J. Mineral, 8:193-208.

Turner R.E., Malita W.A., Nalepka R.F. 1971. Importance atmospheric scattering or everything you've always wanted to know about atmospheric scattering but were afraid to ask. In: Intern. Symp. Remote Sensing of the Environ, 20, Proceeding, 3:1651-1697.

Vialon P., Ruhland M., Grolier J. 1976. Eléments de tectonique analytique. Paris, Masson, $118 \mathrm{p}$.

Zalán P.V., WolffS., Conceição J.C., Astolfi M.A.M., Vieira I.S., Appi C.T, Zanotto O.A. 1987. Tectônica e sedimentação da Bacia do Paraná. In: SBG, Simp. Sul-Bras. Geol., 3, Atas, v. 1, p. 441-447.

Zalán P.V., Wolff S., Conceição J.C., Marques A., Astolfi M.A.M., Vieira I.S., 1990. A Bacia do Paraná. In: Gabaglia G.P.R. \& Milani E.J. (eds.) Origem e evolução de bacias sedimentares. Rio de Janeiro, Petrobras/SEREC/CENSUD, p. 135-168.

Manuscrito ID 12076 Recebido em: 25/08/2008 Aprovado em: 01/02/2010 